\title{
Identificação fenotípica e genotípica de enzimas metalo- $\beta$-lactamases em cepas de Acinetobacter spp
}

\author{
Mohana Trindade ${ }^{1}$, Jane Renner ${ }^{2}$ \\ ${ }^{1}$ Acadêmica do curso de farmácia (Unisc) \\ ${ }^{2}$ Professora do curso de farmácia (Unisc), Doutora em biologia celular \\ e molecular (PUC-POA), Santa Cruz do Sul - RS - Brasil
}

janerenner@unisc.br

Acinetobacter spp nas últimas décadas tem aumentado sua importância como patógeno oportunista, principalmente em ambiente nosocomial. Acinetobacter spp sobrevive por longos períodos em uma ampla gama de condições ambientais. $\mathrm{O}$ aumento da resistência aos antimicrobianos entre isolados de Acinetobacter tem sido documentada. A resistência aos carbapenêmicos entre este patógeno se tornou um problema terapêutico mundial e a produção de metallo- $\beta$-lactamases $(\mathrm{M} \beta \mathrm{L})$ tem emergido como um dos mecanismos responsáveis por essa resistência. O objetivo do presente estudo foi avaliar fenotipicamente e genotipicamente genes que produzem metallo- $\beta$-lactamases em Acinetobacter spp. Este estudo incluiu isolados de amostras biológicas do Hospital Santa Cruz (HSC) a partir de janeiro de 2008 a janeiro de 2010 e do Hospital Universitário de Londrina a partir de janeiro de 2003 a janeiro de 2005. Um total de 21 cepas de Acinetobacter spp foram identificadas através de técnicas microbiológicas e testes de susceptibilidade microbiana. A presença de metallo- $\beta$-lactamase foi investigada pelo teste de disco aproximação e por PCR (genes blaIMP-1,

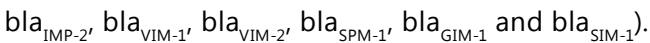
A maioria das amostras $(90,48 \%)$ foram coletadas na UTI de ambos os hospitais incluídos no estudo e eram predominantemente de aspirado traqueal (90,48\%). As amostras do Hospital Universitário de Londrina foram resistentes a maioria dos antibióticos testados, exceto tigeciclina; e as amostras do
Hospital Santa Cruz também foram resistentes à maioria dos antibióticos testados, exceto polimixina $\mathrm{B}$ e tigeciclina. Embora os resultados para a confirmação de MBL por métodos fenotípicos foram considerados contraditórios, o teste de disco aproximação apresentou duas cepas positivas para a produção desta enzima em Acinetobacter spp, sendo estas duas amostras provenientes do Hospital Universitário de Londrina. Das 21 amostras testadas, 14 foram confirmadas como produtoras de enzima bla $_{\text {IMP- } 1 \text {, }}$ sendo 7 delas provenientes do Hospital Santa Cruz e as outras 7, do Hospital Universitário de Londrina; e 4 amostras apresentaram o produto de PCR compatível com o fragmento amplificado do gene bla $\mathrm{VII}_{\mathrm{V}-1}$, sendo todas provenientes somente do Hospital Universitário de Londrina. Nestes testes as cepas confirmadas como produtoras de $\mathrm{M} \beta \mathrm{L}$ foram resistentes a todos os antibióticos testados, incluindo carbapenems, sendo sensível somente à tigeciclina e polimixina B. Duas cepas, provenientes do Hospital Universitário de Londrina, apresentaram simultaneamente os genes bla IMP-1 $_{\text {e bla }}$ (IIM-1, fato que ainda não havia sido relatado no Brasil para esse microrganismo. O conhecimento dos múltiplos mecanismos de resistência envolvidos com Acinetobacter spp, assim como medidas de controle de infecção nosocomial, controle do uso de antimicrobianos e o conhecimento da epidemiologia local das infecções são fundamentais para se evitar surtos de Acinetobacter spp multirresistente. 